\title{
"Not tested on animals": How consumers react to cruelty-free cosmetics proposed by manufacturers and retailers?
}

\author{
Cindy G. GRAPPE, Cindy LOMBART, Didier LOUIS, and Fabien DURIF
}

\begin{abstract}
Purpose - Animal welfare is increasingly favoured by consumers in their choice of food and cosmetic products, proposed by manufacturers and retailers. This study aims to investigate the impact of the "not tested on animals" claim on consumers' attitude and behavioural intention towards a cosmetic product through an enriched version of Ajzen's Theory of Planned Behaviour.
\end{abstract}

Design/methodology/approach - A between-subjects design has been used. 450 participants were recruited through the social network of a cosmetics and personal hygiene brand in Quebec, Canada, and answered a questionnaire. They were randomly assigned to either a manipulation group $(n=226)$ or a control group $(n=224)$. Data were analysed with Partial Least Squares Structural Equation Modelling.

Findings - This study shows that external (credibility and attitude towards marketing claims) and internal psychological variables (subjective norms and altruistic concerns with animal welfare) influence attitude towards and purchase intention of "not tested on animals" personal care products. More egotistic concerns, such as personal appearance, also explain the formation of attitude towards cruelty-free cosmetics.

Research limitations/implications - This research supplements Ajzen's original model with internal psychological (individuals' concerns with animal welfare and personal appearance) and external (general credibility of cosmetic products claims, credibility of the "not tested on animals" claim and attitude towards this claim) variables. These variables, as suggested by previous research on cosmetics and their claims, improve the understanding of consumer attitude and purchase behaviour patterns.

Practical implications - The study's findings point out the role of companies to increase consumers' knowledge on the significance and transparency of their messages, notably the "not tested on animals" claim. They also stress that policymakers in regions where regulation is unclear should at least punish untruthful communication pertaining to animal testing in cosmetic and personal care products.

Originality/value - Prior studies on cosmetic products did not investigate the difference of consumer attitude formation towards cruelty-free products compared to conventional cosmetic products. Consequently, this research shows that the construction of attitude towards crueltyfree products highly differs from conventional personal care.

Key words Animal welfare, cruelty-free, cosmetics, theory of planned behaviour, credibility, marketing claims

Paper type Research paper

To cite this version:

Grappe C.G., Lombart C., Louis D. and Durif F. (2021), "Not tested on animals": How consumers react to cruelty-free cosmetics proposed by manufacturers and retailers?", International Journal of Retail and Distribution Management, 49, 11, 1532-1553. 


\section{Introduction}

It is now obvious that consumers are increasingly aware of animal welfare in their daily choices. This tendency is observable all over the world. In the United States, $84 \%$ of citizens pay importance to better living conditions for animals (1). In Canada, 47\% consider "very important" that companies treat animals humanly (2). In the European Union, $82 \%$ believe that it is important to protect the welfare of farmed animals and that these animals should be better protected than they are currently (3). The World Organization for Animal Health defines animal welfare as the physical and mental state of an animal, in relation to the conditions in which it lives and dies (4).

To guarantee animal welfare, the food industry offers consumers a plethora of claims and labels (Schröder and McEachern, 2004). This move has been closely followed by efforts in the hygiene and cosmetics sphere (Sheehan and Lee, 2014). A good amount of manufacturers move towards the adoption of "cruelty-free" or "not tested on animals" claims. Indeed, these messages appear as the major acquisition vector for 57\% of Americans when selecting a cosmetic product (5). Retailers also commit to defend the animal cause, even if this pattern is more observable in the food industry.

Meanwhile, governments tend to a reduction, if not a ban of tests on animals (Sreedhar et al., 2020). In 2020, 39 countries (including the entirety of the European Union) have already adopted laws banishing these tests in the cosmetics area. The rest of the world does not oblige nor forbid them (e.g., in Canada and in most US states). Animal testing is only legally required in China, whether a Chinese or a foreign brand wishes to market its products in mainland China. This can lead consumers to question the essence of their purchases. For example, a brand can be qualified as "cruelty-free" if it sells its products in the UE, but if it also distributes them in mainland China, some clients might stop considering it as crueltyfree.

Prior research on cosmetics and personal care products suggested that certain values may influence formation of consumers' attitude and behaviour by encouraging them to look for products that will satisfy their values (Grunert and Juhl, 1995). For instance, health, environmental and appearance concerns may explain attitude towards buying organic cosmetics (Kim and Chung, 2011; Photcharoen et al., 2020). Regarding cruelty-free cosmetics, they benefit very high attitudinal and behavioural evaluations, and concerns for animal rights and animal well-being may play a central role in these preferences (Sheehan and Lee, 2014).

However, prior studies on cruelty-free cosmetics lack reliable and sufficient explanation of the attitude and purchase intention towards products that have not been tested on animals (Sheehan and Lee, 2014). Consequently, the objective of this research is to investigate the impact of the "not tested on animals" claim on consumers' attitude and behavioural intention towards a cosmetic product through Ajzen's (1985) Theory of Planned Behaviour (TPB). The latter has been enriched by internal psychological (individuals' concerns with animal welfare and personal appearance) and external (general credibility of cosmetic products claims, credibility of the "not tested on animals" claim and attitude towards this claim) variables, as suggested by previous research on cosmetics (Marcoux, 2000; Hamzaoui-Essoussi and Zahaf, 2008) and their claims (Wansink et al., 2004; Binninger, 2017). 
While altruistic and egoistic values have rarely been put together as explanatory cues of attitudinal formation of cosmetics preferences (Kim and Chung, 2011), this research will consider both concerns for animal welfare and personal appearance as potential and plausible influences in the development of positive attitude towards cruelty-free cosmetics (Sheehan and Lee, 2014). Moreover, prior studies in this field of research did not investigate the difference of consumer attitude formation towards cruelty-free products compared to conventional personal care (Schuitema and De Groot, 2015). Consequently, this research will show that the construction of attitude towards cruelty-free products differs from conventional cosmetics. It will apprehend attitudinal development through a cognitive progression where beliefs define attitude, leading to the delineation of intention, which guides behaviour (Ajzen, 1991). It will develop a linear model explaining attitude and purchase intention of cruelty-free personal care products based on credibility granted to claims used on cosmetics labels and ads in general as well as to cruelty-free claims credibility, leading to attitude towards the "not tested on animal" claim.

From a theoretical point of view, this research complements the founding work of Ajzen on prediction of an individual's intention to engage in a behaviour with variables both internal and external to the psychology of the consumer (e.g., individuals' concerns with animal welfare and personal appearance, and perceived credibility of claims and associated products). It also illustrates the differences in consumers' attitude and purchasing behaviour formation for cruelty-free products compared to conventional cosmetics. From a managerial point of view, this research will point out the educational responsibility of brands to consumers to promote transparency, fluency and understanding ability regarding labels and messages, notably the "not tested on animals" claim. Brands should also reach for official, independent, third-party certifications and labelling systems to be perceived by consumers as more socially responsible.

The remainder of the article is organized as follows. First, a literature review on animal welfare and labelling referring to the "cruelty-free" notion is proposed. Then, the applied theoretical framework, the posited hypotheses and the research model are discussed. The executed data collection, the conducted experiment and the measurement scales used are described. Lastly, the results, their theoretical and managerial contributions as well as the limits of the research are considered. Future research avenues are also proposed.

\section{Claims and labels about animal welfare}

\section{Animal welfare}

Animal welfare has benefited from a lot of researchers' attention, but principally in the food industry. They pointed out that consumers were dissatisfied with breeding and animal wellbeing standards (e.g., Fernqvist and Ekelund, 2014; Ortega and Wolf, 2018). Consumers require brands that go beyond these norms (Te Velde et al., 2002) such as giving access to "natural" living conditions, ensuring the health of the animals, respecting their biological functions (Spooner et al., 2014) or prioritizing small family-scaled farming (Gracia and deMagistris, 2016).

In order to encourage improved practices, some consumers declared to be ready to spend more (e.g., from 19 to $23 \%$ according to Gracia et al. (2011)). Animal welfare has indeed a purchase leveraging effect for organic products (Honkanen et al., 2006; Zander and Hamm, 2010; Akaichi et al., 2019) and stands for quality and food well-being (Binninger, 
2017). However, a lack of knowledge subsists concerning animal welfare (Schröder and McEachern, 2004; Spooner et al., 2014). The concept is recurrently confused with organic, local perceptions (Dahlhausen et al., 2018), good taste, health, pleasing sensations (Van Riemsdijk et al., 2017) and naturality (Borkfelt et al., 2015).

\section{Claims and labels}

In the personal care area, few researchers reflected upon the question of animal welfare (Liobikienè et al., 2016; Photcharoen et al., 2020). However, brands offer consumers a myriad of labels (e.g., logos with bunnies) and claims, including negatively framed messages (e.g., "cruelty-free," "not tested on animals"), shedding light on the absence of dangerous or controversial ingredients or processes because of a public opprobrium (Darke and Ritchie, 2007). This aims to transform consumers' emotional response into an actual act of purchasing (Li and Chapman, 2012). Animal-friendly claims and labels elevate brands' perceptions (Sheehan and Lee, 2014). For instance, Lancendorfer et al. (2008) proved that a simple iconography depicting a dog led consumers to have a positive brand image. Labels and claims referring to the "cruelty-free" idea often call on emotional pondering, the same way do products playing with pastoral visuals (Amos et al., 2014) or even with cuteness appeals via a graphic dynamic (Wang et al., 2017). Yet, they may fail to provide tangible proofs (Carlson et al., 1993).

Some consumers are easily affected by animal-friendly claims and associated labels (Honkanen et al., 2006). The wording "cruelty-free" has been proved to be a "call-for-action" term. It acts as a powerful heuristic in consuming choices, and proves to be a purchasing vector especially when egoistic attributes (price, familiarity, knowledge) are fulfilled (Schuitema and De Groot, 2015). In general, consumers find these "negatively framed" messages substantiated, instructive and important (Newburger, 2009). This is supported by established typology of cosmetics (Fowler et al., 2015). Allegations referring to the absence of tests conducted on animals (e.g., "not tested on animals") are largely considered as acceptable from a semantic standpoint, and thus easily decryptable by consumers. These messages as well as associated labels (e.g., logos with bunnies) hit an almost unanimous recognition rate (Ormandy and Schuppli, 2014).

\section{Theoretical framework, hypotheses and research model}

\section{Theory of planned behaviour}

To grasp consumers' attitude and behaviour towards the purchase of products with a "not tested on animals" claim, the TPB (Ajzen, 1985) has been favoured. In this research, the universally understood claim "not tested on animals" (Sheehan and Lee, 2014) has been preferred to the "cruelty-free" wording. Although more popular in the industry, more often do consumers perceive it as vague (Hastak and Mazis, 2011). The TBP is largely recognized as a valuable tool to shed light on deciding factors of purchase intention in the cosmetic and hygiene area for organic cosmetics (Kim and Chung, 2011; Photcharoen et al., 2020), green skincare (Hsu et al., 2017) or even conventional products (Lu and Chen, 2017). Although prior research has covered the understanding of some cosmetic claim trends, it is void of interest towards cruelty-free products.

The TPB explains the adoption or non-adoption intention of a behaviour through the attitude held towards this behaviour, perceived behavioural control and subjective norms. 
This model allows the study of the influence of consumers' attitude on their behavioural intention as well as the influence of normative beliefs, subjective norms, and perceived behavioural control. Moreover, Ajzen's original model has been supplemented with both internal psychological (individuals' concerns with animal welfare and personal appearance) and external (general credibility of cosmetic products claims, credibility of the "not tested on animals" claim and attitude towards this claim) variables. These variables, suggested by previous research on cosmetics (Marcoux, 2000; Hamzaoui-Essoussi and Zahaf, 2008) and their claims (Wansink et al., 2004; Binninger, 2017), will improve the understanding of consumers' attitude and purchase behaviour.

\section{Perceived behavioural control, subjective norms, attitude and purchase intention}

Attitude towards a behaviour denotes "the level of favourable or unfavourable evaluation of a certain behaviour" (Ajzen, 1991). Consumers' attitude often acts as mediator in the link between their values and their behaviour (Shim and Eastlick, 1998) and the more a person has a positive attitude towards the adoption of a behaviour, the more he will be prone to adopt it (Ajzen, 1985). As far as the cosmetic and personal hygiene industry is concerned, it has been shown that attitude positively influences purchase intention of an organic cosmetic product (Kim and Chung, 2011; Photcharoen et al., 2020), of green skincare (Hsu et al., 2017), of free from parabens cosmetics (Hansen et al., 2012) and even conventional hygiene products (Lu and Chen, 2017). Considering these previous works, this research posits the following hypothesis:

H1: Consumers' attitude towards a "not tested on animals" cosmetic product has a positive influence on their purchase intention of this product.

Behavioural control is "the perceived easiness or difficulty in adopting a behaviour." The more a person perceives a high level of personal control, the more he tends to reveal high behavioural intention relating to the adoption of a given behaviour (Ajzen, 1991). Previous research has used different variables pertaining to situational factors when delineating perceived control of cosmetics buying such as price (Kim and Chung, 2011), confidence and time (Hsu et al., 2017), and convenience (Photcharoen et al., 2020). However, an important part of labeled products choice making lacks thorough insight: level of involvement and trust brought by comprehension (Petty and Cacioppo, 1986; Chaiken et al., 1989). A high level of involvement in the buying decision positively influences messages' efficacy.

Strategies based on logic and sound demonstrations are the most efficient and influent concerning purchase behaviour, especially when a consumer's level of involvement is high, and conversely, one with low levels of involvement will use peripheral signals and heuristics (Chaiken et al., 1989). Some have tested such variables in cosmetics (Lu and Chen, 2017) or green products buying contexts (Liobikienè et al., 2016). In this research, perceived behavioural control is thus envisioned as the level of reading and of comprehension of labels and tags of cosmetic products (Roe et al., 1999), as well as the interest in reading deciphering them (Petty and Cacioppo, 1986; Hsu et al., 2017). According to Ajzen (1991), it should positively affect attitude and purchase intention of cruelty-free cosmetic products even if few studies apprehend perceived behavioural control as inducing both positive attitude and behavioural intention - only the latter has been scrutinized (Kim and Chung, 2011). Accordingly, we hypothesize that: 
H2: Perceived behavioural control has a positive influence on consumers' attitude towards a "not tested on animals" cosmetic product (a) and their purchase intention of this product $(b)$.

Finally, subjective norms reflect peer influence and characterize "the perceived social pressure in the adoption or non-adoption of a behaviour" (Ajzen, 1991). Peer pressure and the desire to be positively perceived by others have been proved as a valid influence of purchase intention of organic (Kim and Chung, 2011; Photcharoen et al., 2020), free from parabens (Hansen et al., 2012), green (Hsu et al., 2017), and conventional cosmetic products (Lu and Chen, 2017). Indeed, psychosocial perspectives are significant reasons for positive attitude and purchase intention of cosmetic products (Hillhouse et al., 2000). Still, previous research has mainly only grasped subjective norms influence on behavioural intention and rarely on attitude as well. However, we offer the following hypothesis:

H3: Subjective norms have a positive influence on consumers' attitude towards a "not tested on animals" cosmetic product (a) and their purchase intention of this product $(b)$.

\section{Personal concerns with animal welfare and appearance}

In order to sharpen the understanding of attitude and purchase behaviour towards cosmetics displaying claims, and especially the "not tested on animals" allegation, it has been considered appropriate to include variables reflecting personal interests. Indeed, if consumers purchase cosmetic products for hygiene purposes, they also do so to modify their appearance (Marcoux, 2000) or/and because they aspire to be eco-friendly and respect animal welfare (Hamzaoui-Essoussi and Zahaf, 2008).

Literature has often classified these motivations into two major categories: "egoistic" concerns, based on individualism, appearance and personal health, and "altruistic" concerns, referring to the protection of the environment or of animals (Padel and Foster, 2005). Researchers have validated the influence of such values on attitude towards cosmetics, specifically health concerns when choosing organic or natural products (Kim and Chung, 2011; Photcharoen et al., 2020), appearance consciousness and hedonism, materialism, selfidentity and self-transcendence for free from cosmetics or environmental concerns and conservation values for organic, eco-friendly beauty products (Kim and Chung, 2011; Hansen et al., 2012). However, none focuses on a value system effect on intention.

In regard to cruelty-free personal hygiene products, Sheehan and Lee (2014) have preliminarily posited, by means of a qualitative research, that support of animal rights is positively correlated with both attitude and purchase intention of cruelty-free brands. Consequently, preoccupations about animal welfare (Honkanen et al., 2006; Nisbet et al., 2009) and personal appearance (Todd, 2004) have been incorporated in our research model. We consider that these psychological variables, internal to consumers' personal beliefs, can have an influence on their appreciation and behaviour. According to Fishbein (1963), beliefs influence the adoption intention of a behaviour as well as the adoption in itself. Thus, we posit the following hypotheses:

H4: Concerns pertaining to animal welfare have a positive influence on consumers' attitude towards a "not tested on animals" cosmetic product (a) and their purchase intention of this product (b). 
H5: Concerns pertaining to personal appearance have a positive influence on consumers' attitude towards a "not tested on animals" cosmetic product (a) and their purchase intention of this product (b).

\section{Credibility and attitude towards the «not tested on animals » claim}

Ajzen's original model has also been enriched with external variables to the consumer's psychology envisioned as a linear model explaining attitude and purchase intention of crueltyfree cosmetic products. This is substantiated by the exploration of the level of credibility granted to claims used in personal care in general and to the "not tested on animals" message specifically. Indeed, the credibility of a given message is considered as a key factor in its own understanding (Heesacker et al., 1983).

Several factors are likely to influence beliefs accorded to claims, comprising familiarity with the product or the brand. For instance, prior knowledge of a claim helps to simplify the information and can lead to a fairer interpretation. MacKenzie and Lutz (1989) have tested and validated the fact that perceived credibility of ads in general positively influenced credibility of a particular advertising stimulus on a given exposition occasion as well as consumers' attitude towards this stimulus. A person not believing in the veracity of a message will be less likely to adopt a positive attitude towards the product displaying it and to embrace any kind of buying intention. This reasoning could be extrapolated to cosmetic claims and, most specifically, to those referring to the lack of animal testing. Therefore, we hypothesize that:

H6: General credibility of cosmetic products claims has a positive influence on credibility of the "not tested on animals" claim (a) and consumers' attitude towards this claim (b).

For a label or a claim to be efficient and plausible, it is critical that it rapidly translates into a personal relevant interest for the consumer, whether pertaining to his health, the quality of the product or cost-effectiveness (Binninger, 2017). Since short and simple claims are considered as more persuasive cues during purchase decision, it is because they often refer to a particular attribute and not to the product in its entirety. Moreover, more concise and straightforward claims reach out to all consumers whether they are concerned and interested in the message or not (Wansink et al., 2004). Holbrook (1978) has also shown that perceived credibility of a given message significantly contributes to the prediction of an attitude towards a claim. Furthermore, a message credibility has a direct and significant positive impact on attitude towards this message (Choi and Rifon, 2002). Consequently, we propose the following hypothesis:

H7: Credibility of the "not tested on animals" claim has a positive influence on consumers' attitude towards this claim.

Lastly, several studies indicated that consumers' attitude towards a particular ad has a positive and significant influence on their attitude towards the brand (Goldsmith et al., 2000; Choi and Rifon, 2002). Indeed, ad perception and favourable or unfavourable attitude have a direct effect on attitude towards the brand related to the ad (MacKenzie and Lutz, 1989). Building upon this analogy, we conjecture that: 
H8: Consumers' attitude towards the claim "not tested on animals" has a positive influence on their attitude towards the product displaying this claim.

Figure 1 offers a synthesis of the research hypotheses.

[insert Figure 1 around here]

\section{Methodology}

\section{Data collection}

A cosmetics and personal hygiene brand in Quebec, Canada allowed us to use its social network to post a link with our questionnaire. We asked the brand's customers to answer questions on cosmetic/personal care products and their habits. With the help of a filter question on their purchasing and consumption habits of cosmetics and personal care, only users of this product category were allowed to answer the questionnaire. 450 actual buyers and consumers of cosmetic/personal care products were integrated in our research (response rate: $94 \%)$.

The respondents' average age in our sample is 30.6 years old and most are women (82.6\%), which corresponds to the brand's target. $50.7 \%$ are single and $48.5 \%$ common-law or married. Both groups are homogeneous in terms of sex $\left(\chi^{2}=1.113 ; \mathrm{p}\right.$-value $\left.=0.291\right)$, age $\left(\chi^{2}=0.127 ; \mathrm{p}\right.$-value $\left.=0.722\right)$ and status $\left(\chi^{2}=2.277\right.$; $\mathrm{p}$-value=0.685). Table 1 presents the respondents' socio-psychographic characteristics of the experimental groups formed.

[insert Table 1 around here]

\section{Experimental design}

A between-subjects design has been used. The 450 participants of our research were randomly assigned to either a manipulation group $(n=226)$ or a control group $(n=224)$. When answering our questionnaire, the participants of the manipulation group $(n=226)$ had to consider a shampoo bottle with the claim "not tested on animals" added on it, whereas the participants of the control group $(n=224)$ had to reflect on the same product, but without any claim on the bottle.

A shampoo bottle had been chosen for its suitability for all kinds of consumers, indiscriminately of sex, age or other characteristics. The penetration rate of hair products is high worldwide (i.e., more than $80 \%$ in North America). The same shampoo bottle, without reference to any brand to avoid introducing bias into the judgment of the cosmetic product proposed, was submitted to the respondents of the control group and manipulation group, except that the bottle of the manipulation group had the claim "not tested on animals" added on it.

Measurement scales 
Attitude towards the cosmetic product was measured by three items adapted from the brand attitude measurement scale of Lombart and Louis (2012). Consumer purchase intention of the cosmetic product was measured by four items taken from the behavioural-intentions battery proposed by Zeithaml et al. (1996). Subjective norms and perceived behavioural control were measured respectively by three and two items adapted from the scales of Redondo Palomo et al. (2015) that measure these two variables towards green skincare products. Consumers' concerns with animal welfare were measured by three items taken from the scale of Herzog et al. (1991) developed to measure consumer attitudes towards the use of animals. Consumers' concerns with personal appearance were measured by four items taken from the appearance schemas inventory proposed by Cash and Labarge (1996).

The credibility of claims displayed on cosmetic products in general was measured by three items adapted from the general advertising credibility scale proposed by MacKenzie and Lutz (1989). The credibility of the studied claim was assessed through four items adapted from the perceived credibility of a quality label developed by Moussa and Touzani (2008). The attitude towards the "not tested on animals" claim was measured by four items adapted from the scale introduced by Maheswaran and Meyers-Levy (1990) to determine consumers' attitude towards the adoption of an advocated behaviour. Both groups answered to all our questionnaire's items, except to those related to the presence of claims on cosmetic products (in general or the one studied) for the control set. The items used in this study are available in table 2 .

\section{Data analysis}

In this research, we used partial least squares structural equation modelling (PLS-SEM) and a bootstrap procedure with 5,000 replications (Tenenhaus et al., 2005), to analyse our data. We used PLS-SEM (with the software XLSTAT 2020), referred to as variance-based, instead of covariance-based structural equation modelling (CB-SEM) (Hair et al., 2017), for two main reasons stressed by Hair et al. $(2012,2014)$ in their meta-analyses on the use of PLS-SEM in marketing research. PLS-SEM does not require the variables to follow a multivariate normal distribution. Computed Mardia's coefficient is superior to $|3|$ in this research. PLS-SEM allows working with small samples. The sample sizes are equal to 224 and 226 for the two groups considered in this research (control and manipulation respectively) with a mean of 211.29 in the marketing field. PLS-SEM also allows working with models that include a large number of latent variables; indeed, our research model contains nine variables with an average number of 7.94 in the marketing field.

First, the measurement models were tested. Confirmatory factor analyses examined the unidimensional factor structure of the measurement scales used. Their reliabilities (Cronbach's alpha (Cronbach, 1951) and Jöreskog's rhô (Jöreskog, 1971) coefficients) as well as their convergent (average variance extracted (AVE); Fornell and Larcker, 1981) and discriminant (heterotrait-monotrait (HTMT) method; Henseler et al., 2015) validities were also assessed. Then, the structural models were tested. We followed the recommendation of Hair et al. (2019) to report our results. To test the mediating effects postulated, the procedure advocated by Cepeda et al. (2018), specifically developed for PLS-SEM, was used. The significance of a direct effect $\left(c^{\prime}\right)$ and an indirect effect $(a \times b)$ were estimated.

\section{Results}

Test of the measurement models 
Confirmatory factor analyses established the unidimensional factor structure of the measurement scales used. The loadings, that are greater than 0.5 and statistically significant at the 1\% level, are satisfactory (Table 2). Then, Cronbach's alpha (Cronbach, 1951) and Jöreskog's rhô (Jöreskog, 1971) coefficients indicated the reliability of the measurement scales used. The coefficients calculated are above the threshold of 0.7 and thus satisfactory (Table 3). Lastly, the approach advocated by Fornell and Larcker (1981) established the convergent validity of the measurement scales used. The AVE are above the threshold of 0.5 (see Table 3). The discriminant validity of the measurement scales used was established through the HTMT method, as recommended by Henseler et al. (2015) for variance-based SEM. The values in table 4 are below the 0.85 threshold.

\section{Test of the structural models}

[insert Tables 2, 3 and 4 around here]

The SEM method enables to estimate complex models with many variables and structural paths. Linear independent-dependent relationships between several variables are examined in a path model. The structural model path coefficients (PC) for the relationships between the variables are thus derived from estimating a series of regression equations. The path coefficients have standardized values approximately between -1 and +1 . Estimated path coefficients close to +1 represent strong positive relationships (and vice versa for negative values) that are usually statistically significant. The closer the estimated coefficients are to 0 , the weaker are the relationships that are usually not statistically significant. Whether a coefficient is significant depends on its $t$ value. When a $t$ value is larger than a critical value, researchers can conclude that the coefficient is statistically significant at a certain error probability, i.e., significance level (i.e., a $t$ value greater than $|2.575 / 1.96|$ indicate that the path coefficient is significant at the $1 / 5 \%$ level). The examination of the values of the path coefficients and their significance level in table 5 indicates the causal relationships between the different variables considered.

Hereafter, we present the results related to the manipulation group ( $n=226)$ (Figure 2), with the claim "not tested on animals" on the cosmetic product.

Firstly, the credibility of claims on cosmetic products in general has a positive and significant impact on consumers' attitude towards this claim $(\mathrm{PC}=0.373 ; t=3.792 ; \mathrm{p}<0.01)$. Hypothesis H6b is supported by our data. The credibility of the studied claim has also positive and significant impact on consumers' attitude towards this claim, but to a lesser extent ( $\mathrm{PC}=0.230 ; t=2.365 ; \mathrm{p}<0.05)$. Hypothesis $\mathrm{H} 7$ is validated. By contrast, the credibility of claims on cosmetic products in general does not have a significant impact on the credibility of the studied claim ( $\mathrm{PC}=0.179$; non-significant (ns)). Hypothesis H6a is not supported by our data. In this research, the impact of the credibility of claims displayed on cosmetic products in general on consumers' attitude towards the studied claim (i.e., "not tested on animals") is direct. It is not mediated, partially or fully, by the credibility of the studied claim, as MacKenzie and Lutz's (1989) seminal work might have suggested.

In essence, the credibility of claims on cosmetic products in general and the credibility of the studied claim (i.e., "not tested on animals") explain $21.3 \%$ of consumers' attitude towards this claim. 
Secondly, consumers' attitude towards the "not tested on animals" claim has a positive and significant impact on their attitude towards the cosmetic product with this claim $(\mathrm{PC}=0.356 ; t=3.747 ; \mathrm{p}<0.01$ ). Hypothesis $\mathrm{H} 8$ is supported by our data. Subjective norms have also a positive and significant impact on consumers' attitude towards the cosmetic product with the claim "not tested on animals" ( $\mathrm{PC}=0.387 ; t=3.852 ; \mathrm{p}<0.01)$. Hypothesis H3a is validated. Although it can be assumed that shampoo is a product used in a private, intimate setting, the sample's young age could eventually lead to a group purchase context and explain these results. Finally, consumers' concerns with animal welfare have a positive and significant impact on consumers' attitude towards the cosmetic product with the claim "not tested on animals" ( $\mathrm{PC}=0.314 ; t=3.343 ; \mathrm{p}<0.01$ ). Hypothesis $\mathrm{H} 4 \mathrm{a}$ is supported by our data. Similarly, consumers' concerns with personal appearance $(\mathrm{PC}=0.281 ; t=3.330 ; \mathrm{p}<0.01)$ have also a positive and significant impact on consumers' attitude towards a cosmetic product displaying the claim "not tested on animals". Hypothesis H5a is validated. Our study confirms the founding work of Todd (2004). By contrast, perceived behavioural control does not have an impact on consumers' attitude towards the cosmetic product with the claim "not tested on animals" ( $\mathrm{PC}=0.001 ; \mathrm{ns})$. Hypothesis $\mathrm{H} 2 \mathrm{a}$ is not supported by our data.

Fundamentally, consumers' attitude towards the "not tested on animals" claim, subjective norms and consumers' concerns with animal welfare and personal appearance explain $42.6 \%$ of consumers' attitude towards the cosmetic product with the claim "not tested on animals". According to computed path coefficients, the impacts of these four variables on consumers' attitude towards the cosmetic product with the claim "not tested on animals" seem similar.

Thirdly, consumers' attitude towards the cosmetic product with the claim "not tested on animals" has a positive and significant impact on their purchase intention of this product ( $\mathrm{PC}=0.406 ; t=5.202 ; \mathrm{p}<0.01$ ). Hypothesis $\mathrm{H} 1$ is validated. This finding is consistent with previous conclusions relating to conventional hygiene products ( $\mathrm{Lu}$ and $\mathrm{Chen}, 2017$ ), green skincare (Hsu et al., 2017), organic cosmetics (Kim and Chung, 2011; Photcharoen et al., 2020) or free-from parabens personal care products (Hansen et al., 2012) while broadening them to cruelty-free cosmetics. Subjective norms have also a positive and significant impact on consumers' purchase intention of a "not tested on animals" cosmetic product $(\mathrm{PC}=0.360$; $t=4.253 ; \mathrm{p}<0.01)$. This finding supports hypotheses $\mathrm{H} 3 \mathrm{~b}$ while confirming and extending to cruelty-free cosmetics the previous relations formulated in the works of $\mathrm{Lu}$ and Chen (2017) on conventional and green cosmetics, Kim and Chung (2011) and Photcharoen et al. (2020) on organic personal care products, and Hansen et al. (2012) on free-from parabens products. Finally, consumers' concerns with animal welfare have a positive and significant impact on consumers' purchase intention of a "not tested on animals" cosmetic product $(\mathrm{PC}=0.260$; $t=3.663 \mathrm{p}<0.01$ ), supporting hypotheses $\mathrm{H} 4 \mathrm{~b}$.

Conversely, consumers' concerns with personal appearance does not have an impact on consumers' purchase intention of this cosmetic product $(\mathrm{PC}=-0.028$; ns), rejecting hypothesis H5b. This impact is fully mediated by consumer attitude. This significant mediating effect has been confirmed by the procedure developed by the Cepeda et al. (2018). Preoccupations regarding personal appearance, as suggested by Marcoux (2000) for conventional cosmetics, have only an indirect impact in our study, mediated by the concept of attitude. Similarly, perceived behavioural control does not have a significant impact on consumers' purchase intention of a "not tested on animals" cosmetic product ( $\mathrm{PC}=-0.029$; ns). Hypotheses $\mathrm{H} 2 \mathrm{~b}$ is not supported by our data. Recall that in this research, perceived behavioural control was envisioned as the level of reading and comprehension of labels and 
tags of cosmetic and personal care products (Roe et al., 1999), as well as the interest in deciphering them (Petty and Cacioppo, 1986; Hsu et al., 2017). Low levels of involvement could explain this outcome (Petty and Cacioppo, 1986; Chaiken et al., 1989). According to Anderson and Lavallee (2008) and Hansen et al. (2012), consumers' involvement level in their choice of cosmetic and hygiene products is oftentimes low.

Essentially, consumers' attitude towards the cosmetic product with the claim "not tested on animals", subjective norms and consumers' concerns with animal welfare explain $63.2 \%$ of consumers' purchase intention of a "not tested on animals" cosmetic product. According to computed path coefficients, consumers' attitude towards the cosmetic product with the claim "not tested on animals" and subjective norms have the strongest impacts. The impact of consumers' concerns with animal welfare is significant but seems less important.

For the control group $(n=224)$ (Figure 3), the analyses performed indicate that subjective norms have a strong positive and significant impact on consumers' attitude towards the claim-free conventional cosmetic product $(\mathrm{PC}=0.748 ; t=10.969 \mathrm{p}<0.01)$ and on their purchase intention of this product $(\mathrm{PC}=0.596 ; t=6.184 ; \mathrm{p}<0.01)$. Then, to a lesser extent, consumers' attitude towards the cosmetic product without a specific claim has a positive and significant impact $(\mathrm{PC}=0.289 ; t=2.862 ; \mathrm{p}<0.01)$ on their intention to buy it. The model tested explains $62.9 \%$ of consumers' attitude towards the claim-free conventional cosmetic product and $62.1 \%$ of their purchase intention of this product.

\author{
[insert Table 5 around here] \\ [insert Figures 2 and 3 around here]
}

\title{
Discussion
}

The research's main goal was to explain attitude and behaviour towards cruelty-free products, compared to conventional products, through the theory of planned behaviour (Ajzen, 1985), enriched with external variables to the consumer's psychology such as credibility and attitude towards the "not tested on animals" claim, both linked to the brand's manipulation of the claim, as well as variables internal to the reasoning process, in our case, concerns with animal welfare and personal appearance.

Firstly, our study illustrates that when consumers disclose a positive perception of credibility of cosmetics claims in general and specifically the "not tested on animals" one, their attitude towards the cosmetic product with this claim will increase. This research thus confirms and extends to cosmetic claims and, most specifically, to those referring to the lack of animal testing, the founding work of MacKenzie and Lutz (1989) who indicated that perceived credibility of ads in general positively influenced credibility of a particular advertising stimulus on a given exposition occasion as well as consumers' attitude towards this stimulus. Similarly, it confirms and extends to personal care labelling, and most specifically to the claim "not tested on animals", the works of Holbrook (1978) and Choi and Rifon (2002). These authors highlighted that perceived credibility of a given message has a direct and significant positive impact on attitude towards this message. Further, our results establish an alikeness between a claim and a product in the relationship between attitude towards a stimulus (i.e., an ad) and the positive attitude towards the related brand it creates, as illustrated by Goldsmith et al. (2000). 
Our results also indicate that when consumers unveil psychosocial internal values for animal well-being and personal appearance, it will have a positive impact on their attitude towards a cosmetic product with a cruelty-free message, and subsequently on their purchase intention (directly or mediated by attitude.) This research thus quantitatively confirms Sheehan and Lee's (2014) preliminary conclusions about cruelty-free personal care products supporting that endorsing animal rights is positively correlated with both attitude and purchase intention of cruelty-free brands. In essence, consumers have the intention to purchase "not tested on animals" cosmetics because of concerns pertaining to animal welfare, as suggested by Hamzaoui-Essoussi and Zahaf (2008). Preoccupations regarding personal appearance, as suggested by Marcoux (2000) for conventional cosmetics, have only an indirect impact in our study, mediated by the concept of attitude.

Finally, in addition to substantiating the impact of external (situational) and internal (individual) variables to the consumer's psychology, this research also shed light on consumers' willingness to consider others' opinion, measured through Ajzen's subjective norms. This study thus enriches previous research as the latter has mainly considered the influence of subjective norms on behavioural intention and rarely on attitude (Kim and Chung, 2011; Hansen et al., 2012; Hsu et al., 2017; Lu and Chen, 2017; Photcharoen et al., 2020). This research also reveals that consumer evaluation of cruelty-free vs. conventional cosmetic products differs in terms of social and personal values. Thus, it supplements prior studies on cosmetic products as the difference of consumer attitude formation towards cruelty-free products compared to conventional cosmetic products has not been examined (Schuitema and De Groot, 2015).

\section{Theoretical implications}

Initially, this research highlights the difference of consumer attitude and buying behaviour formation when encountering cruelty-free products compared to conventional cosmetics. While consumer attitude and purchase intention are only based on subjective norms (i.e., peers' opinions) for personal care free from logos or credence claims, their constructions are far more complex as far as cruelty-free products are concerned. It aligns with the literature that underperforms in explaining attitude and behaviour towards general cosmetics ( $\mathrm{Lu}$ and Chen, 2017).

In addition, this work supplements Ajzen's original model with internal psychological (individuals' concerns with animal welfare and personal appearance) and external (general credibility of cosmetic products claims, credibility of the "not tested on animals" claim and attitude towards this claim) variables. These variables, as suggested by previous research on cosmetics (Marcoux, 2000; Hamzaoui-Essoussi and Zahaf, 2008) and their claims (Wansink et al., 2004; Binninger, 2017), improve the understanding of consumer attitude and purchase behaviour patterns. Consistent with previous research, our study supports the idea that certain value systems are explanatory factors of attitude in the cosmetics area (Grunert and Juhl, 1995; Kim and Chung, 2011; Hansen et al., 2012), and that altruistic and egoistic considerations are not necessarily at odds. Alongside this system, credibility granted to cosmetics claims plays a substantial role in attitudinal development (MacKenzie and Lutz, 1989), proving that message manipulation and situational circumstances can indirectly influence purchase intention and potentially behaviour of cruelty-free personal care. Even though subjective norms also explain a significant part of attitude and buying intention of claim-free cosmetics, importance given to the animal cause, positive attitude towards the "not tested on animals" claim and credibility given to the latest also delineate attitude towards 
cruelty-free products, on top of peer opinion. Seeking others' acceptance reveals a certain social pressure in the consumption of cruelty-free cosmetic products (Sheehan and Lee, 2014; Schuitema and De Groot, 2015). Alternatively, our results could suggest that pursuing consumerism promoting animal welfare is also based on feelings of morality as dictated by the social group (Thøgersen and Ölander, 2003).

Lastly, this study points out that behavioural control, or consistency in reading and the level of understanding labels and claims, has no impact whatsoever on choice of our tested products, unveiling a lack of consumer knowledge pertaining to the meaning of claims and graphic labels used by the industry (Hansen et al., 2012). According to the theory of information economics, we can hypothesize that consumers are imperfectly informed about properties, claims, labels and ingredients of a cosmetic product (Ford et al., 1990). Since personal care is a fast-moving consumer good, it seldom reflects high involvement levels from consumers (Shamsher and Chowdhury, 2012). Consequently, when involvement levels are low, consumers oftentimes use peripherical signals and heuristics, which cruelty-free claims have proved to be (Petty and Cacioppo, 1986; Sheehan and Lee, 2014).

\section{Managerial and public policy implications}

First, our results point to a strong need for companies' education duty related to the significance and transparency of their messages as a consequence of the lack of client recognition and understanding ability regarding claims and existing communication on labels. This is all the more preoccupying as certain "conventional" brands are establishing themselves in the natural and animal well-being market (e.g., by offering vegan formulations) while still testing their products on laboratory animals in places where law compels it or does not forbid testing, creating a double standard that becomes difficult to apprehend from the consumer's point of view. The use of credence claims leads consumers to encounter hardship and hazard when judging the veracity and authenticity of messages and to mix different information pertaining to animal welfare (i.e., vegan (referring to the absence of animal products) vs. cruelty-free (referring to the lack of testing on animals)). However, some brands and retailers have surpassed the "label only" concept by adopting a branding strategy fully integrative of their vision and their attachment to animal welfare (e.g., The Body Shop). Another pertinent strategy, as suggested by previous research, is to collaborate with relevant stakeholders, such as animal-interest organizations, in order to gain additional trust on the product in general (Schuitema and De Groot, 2015).

Second, the stronger a consumer believes a brand or retailer is engaged in sustainable manufacturing or retailing, such as fighting animal testing and promoting animal welfare, through TV spots or in-store digital displays (van Giesen and Leenheer, 2019), with or without underlying proofs and regardless of their interpretation of the claim, the stronger he agrees that this brand or retailer is safer and more socially responsible (Sheehan and Lee, 2014). In the same vein, whether retailers pertain to grocery stores or more specialized channels, offering consumers "responsible" products such as cruelty-free cosmetics and personal care would permit them to enhance their ethical image (Bezençon and EtemadSajadi, 2015) to the most committed clients in the first place. Subsequently, referencing and putting forward cruelty-free products on shelfs would enable retailers to attract and create a relationship with these proactive consumers in order to develop trust, raise their satisfaction levels and retain them provoking loyalty to all their sales points (Lombart and Louis, 2014; Louis et al., 2019). 
Third, in terms of public policies, there exist as many regulations as countries. Consequently, no universal formula can be applied. To sum up, in the European Union, animal testing for cosmetics has been banned in 2013 and the use of claims or logos referring to the absence of thereof has been prohibited in 2019 (6) for remedying the proliferation of misleading cruelty-free claims. Brands have thus an education responsibility and should reach for official, independent, third-party certifications and labelling systems (e.g., Leaping Bunny, PETA, CCF Rabbit) that set a universal standard and combat misleading messages. The latest solution should also be envisioned by companies marketing in countries that do not forbid nor require animal testing of cosmetic products, such as the United States or Canada, as they represent the only truthful engagement and assurance for consumers. Brands have a real interest in putting additional efforts in terms of animal well-being given the power of the "not tested on animals" allegation. Indeed, the terms "cruelty-free" and "not tested on animals" are so highly motivating that consumers use it as a valuable heuristic, even with evidence that the terms may be meaningless (Sheehan and Lee, 2014). Also, policymakers in regions where regulation is unclear should at least punish untruthful communication pertaining to animal testing in cosmetic and personal care products.

\section{Limitations and research avenues}

To begin with, only behavioural intention has been scrutinized in this research. The study of effective behaviour in a retail context or online could lead future research to refine our results, especially in terms of possible differences between intention and adoption, as observed in the responsible consumption literature pertaining to consumers' contradictions, or "green gap" (ElHaffar et al., 2020).

Then, it would be relevant to repeat the experiment with other subjects to reach an age mean and level of education that are more representative of the Quebec (Canada) population, but also in other countries than Canada, with different legislation and regulatory backgrounds. Larger sub-sample sizes would also allow testing of moderation effects, regarding sex (Herzog et al., 1991) and age (Spooner et al., 2014). Further studies could also investigate the respective impacts of the "cruelty-free" and "not tested on animals" claims, and even graphic labels such as homemade bunny logos or official labelling systems, on the enriched model of attitude and purchase intention formation proposed in this research.

Ultimately, additional work could also focus on other external variables such as those linked to the store's environment (merchandising, price, atmosphere, etc.) or to the transactional website's (user experience, price, etc.). This would provide more specific recommendations for retailers and brands. In the same vein, in terms of social influence, it is possible that the apprehension of cosmetic products use in a private sphere could relativize our results. For the purposes of exploring this hypothesis, a group purchase experiment, with or without the presence of accompanying people, could accurately measure the influence of subjective norms for cruelty-free cosmetics in different contexts.

\section{Footnotes}

(1) Opinion Research Corporation. (2016). Natural Food Labels Survey. Consumer Reports National Research Centre.

(2) The Hartman Group. (2015). Sustainability practices: Animal welfare. Sustainability Transparency. 
(3) TNS Opinion \& Social. (2015). Attitudes of Europeans toward Animal Welfare. Special Eurobarometer 442.

(4) World Organisation for Animal Health. (2019). Terrestrial Animal Health Code.

(5) Nielsen. (2015). Package this: Beauty consumers favour 'cruelty free' and 'natural' product claims.

(6) European Council. (2014). Official Journal of the European Union No L 107(5), 5-9.

\section{References}

Ajzen, I. (1985), "From intentions to actions: A theory of planned behavior", in Kuhl J. and Beckmann J. (Eds.), Action-control: From cognition to behavior, Springer, Heidelberg, pp. 11-39.

Ajzen, I. (1991), "The theory of planned behavior", Organizational Behavior and Human Decision Processes, Vol. 50 No. 2, pp. 179-211.

Akaichi, F., Glenk, K. and Revoredo-Giha, C. (2019), "Could animal welfare claims and nutritional information boost the demand for organic meat? Evidence from nonhypothetical experimental auctions", Journal of Cleaner Production, Vol. 207, pp. 961970.

Amos, C., Pentina, I., Hawkins, T. G. and Davis, N. (2014), "Natural' labeling and consumers' sentimental pastoral notion", Journal of Product \& Brand Management, Vol. 23 No. 4/5, pp. 268-281.

Anderson, A.G. and Lavallee, D. (2008), "Applying the theories of reasoned action and planned behavior to athlete training adherence behavior", Applied Psychology, Vol. 57 No. 2, pp. 304-312.

Bezençon, V. and Etemad-Sajadi, R. (2015), "The effect of a sustainable label portfolio on consumer perception of ethicality and retail patronage", International Journal of Retail \& Distribution Management, Vol. 43 No. 4/5, pp. 314-328.

Binninger, A.S. (2017), "Perception of naturalness of food packaging and its role in consumer product evaluation", Journal of Food Products Marketing, Vol. 23 No. 3, pp. 251-266.

Borkfelt, S., Kondrup, S., Röcklinsberg, H., Bjørkdahl, K. and Gjerris, M. (2015), "Closer to nature? A critical discussion of the marketing of "ethical" animal products", Journal of Agricultural and Environmental Ethics, Vol. 28 No. 6, pp. 1053-1073.

Carlson, L., Grove, S.J. and Kangun, N. (1993), "A content analysis of environmental advertising claims: A matrix method approach", Journal of Advertising, Vol. 22 No. 3, pp. 27-39.

Cash, T.F. and Labarge, A.S. (1996), "Development of the Appearance Schemas Inventory: A new cognitive body-image assessment", Cognitive Therapy and Research, Vol. 20 No. 1, pp. 37-50.

Cepeda, G., Nitzl, C. and Roldán, J.L. (2018), "Mediation analyses in partial least squares structural equation modeling: Guidelines and empirical examples", in Hengky L. and Noonan R. (Eds.), Partial least squares structural equation modeling: Basic concepts, methodological issues and applications, Springer, Heidelberg, pp. 173-195.

Chaiken, S., Liberman, A. and Eagly, A.H. (1989), "Heuristic and systematic information processing within and beyond the persuasion context", in Uleman J. S. and Bargh J. A. (Eds.), Unintended thought: Limits of Awareness, Intention, and Control, Guilford Press, New York, pp. 212-252.

Choi, S.M. and Rifon, N.J. (2002), “Antecedents and consequences of web advertising credibility: A study of consumer response to banner ads", Journal of Interactive Advertising, Vol. 3 No. 1, pp. 12-24. 
Cronbach, L.J. (1951), "Coefficient alpha and the internal structure of tests", Psychometrica, Vol. 16 No. 3, pp. 297-334.

Dahlhausen, J.L., Rungie, C. and Roosen, J. (2018), "Value of labeling credence attributescommon structures and individual preferences", Agricultural economics, Vol. 49 No. 6 , pp. 741-751.

Darke, P.R. and Ritchie, R.J. (2007), "The defensive consumer: Advertising deception, defensive processing, and distrust", Journal of Marketing Research, Vol. 4 No. 1, pp. 114-127.

ElHaffar, G., Durif, F. and Dubé, L. (2020), "Towards closing the attitude-intention-behavior gap in green consumption: A narrative review of the literature and an overview of future research directions", Journal of Cleaner Production, Vol. 275, 122556.

Fernqvist, F. and Ekelund, L. (2014), "Credence and the effect on consumer liking of food-A review", Food Quality and Preference, Vol. 32, pp. 340-353.

Fishbein, M. (1963), "An investigation of the relationships between beliefs about an object and the attitude toward that object", Human relations, Vol. 16 No. 3, pp. 233-239.

Ford, G.T., Smith, D.B. and Swasy, J.L. (1990), "Consumer skepticism of advertising claims: Testing hypotheses from economics of information", Journal of Consumer Research, Vol. 16 No. 4, pp. 433-441.

Fornell, C. and Larcker, D.F. (1981), "Evaluating structural equation models with unobservable variables and measurement error", Journal of Marketing Research, Vol. 18 No. 1, pp. 39-50.

Fowler, J.G., Reisenwitz, T.H. and Carlson, L. (2015), “Analyzing deceptiveness of cosmetics claims in fashion ads", In Annual Macromarketing Conference, p. 368.

Goldsmith, R.E., Lafferty, B.A. and Newell, S.J. (2000), "The impact of corporate credibility and celebrity credibility on consumer reaction to advertisements and brands", Journal of advertising, Vol. 9 No. 3, pp. 43-54.

Gracia, A. and de-Magistris, T. (2016), "Consumer preferences for food labeling: What ranks first?”, Food Control, Vol. 61, pp. 39-46.

Gracia, A., Loureiro, M.L. and Nayga, Jr, R.M. (2011), "Valuing an EU animal welfare label using experimental auctions", Agricultural Economics, Vol. 42 No. 6, pp. 669-677.

Grunert, S. C. and Juhl, H. J. (1995), "Values, environmental attitudes, and buying of organic foods", Journal of Economic Psychology, Vol. 16 No. 1, pp. 39-62.

Hair, J.F., Hult, G.T.M., Ringle, C.M. and Sarstedt, M. (2017), A primer on partial least squares structural equation modeling (PLS-SEM). Thousand Oaks, Sage, CA.

Hair, J.F., Risher, J.J., Sarstedt M. and Ringle, C.M. (2019), "When to use and how to report the results of PLS-SEM", European Business Review, Vol. 33 No. 1, pp. 2-24.

Hair, J.F., Sarstedt, M., Hopkins, L. and Kuppelwieser, V.G. (2014), "Partial least squares structural equation modeling (PLS-SEM): An emerging tool in business research", European Business Review, Vol. 26 No. 2, pp. 106-121.

Hair, J.F., Sarstedt, M., Ringle, C.M. and Mena, J.A. (2012), "An assessment of the use of partial least squares structural equation modeling in marketing research", Journal of the Academy of Marketing Science, Vol. 40 No. 3, pp. 414-433.

Hamzaoui-Essoussi, L. and Zahaf, M. (2008), "Decision making process of community organic food consumers: An exploratory study", Journal of Consumer Marketing, Vol. 25 No. 2, pp. 95-104.

Hansen, T., Risborg, M.S. and Steen, C.D. (2012), "Understanding consumer purchase of free- of cosmetics: A value- driven TRA approach", Journal of Consumer Behaviour, Vol. 11 No. 6, pp. 477-486. 
Hastak, M. and Mazis, M.B. (2011), "Deception by implication: A typology of truthful but misleading advertising and labeling claims", Journal of Public Policy \& Marketing, Vol. 30 No. 2, pp. 157-167.

Heesacker, M., Petty, R.E. and Cacioppo, J.T. (1983), "Field dependence and attitude change: Source credibility can alter persuasion by affecting message- relevant thinking", Journal of Personality, Vol. 51 No. 4, pp. 653-666.

Henseler, J., Ringle, C.M. and Sarstedt, M. (2015), "A new criterion for assessing discriminant validity in variance-based structural equation modeling", Journal of the Academy of Marketing Science, Vol. 43 No. 1, pp. 115-135.

Herzog, H.A., Betchart, N.S. and Pittman, R.B. (1991), "Gender, sex role orientation, and attitudes toward animals", Anthrozoös, Vol. 4 No. 3, pp. 184-191.

Hillhouse, J.J., Turrisi, R. and Kastner, M. (2000), "Modeling tanning salon behavioral tendencies using appearance motivation, self-monitoring and the theory of planned behavior", Health Education Research, Vol. 15 No. 4, pp. 405-414.

Holbrook, M.B. (1978), Beyond attitude structure: Toward the informational determinants of attitude, Journal of Marketing Research, Vol. 15 No. 4, pp. 545-556.

Honkanen, P., Verplanken, B. and Olsen, S.O. (2006), "Ethical values and motives driving organic food choice", Journal of Consumer Behaviour: An International Research Review, Vol. 5 No. 5, pp. 420-430.

Hsu, C.L., Chang, C.Y. and Yansritakul, C. (2017), "Exploring purchase intention of green skincare products using the theory of planned behavior: Testing the moderating effects of country of origin and price sensitivity", Journal of Retailing and Consumer Services, Vol. 34, pp. 145-152.

Kim, H. and Chung, J.E. (2011), "Consumer purchase intention for organic personal care products", Journal of Consumer Marketing, Vol. 28 No. 1, pp. 40-47.

Lancendorfer, K.M., Atkin, J.L. and Reece, B.B. (2008), "Animals in advertising: Love dogs? Love the ad!", Journal of Business Research, Vol. 61 No. 5, pp. 384-391.

Li, M. and Chapman, G.B. (2012), "Why do people like natural? Instrumental and ideational bases for the naturalness preference", Journal of Applied Social Psychology, Vol. 42 No. 12, pp. 2859-2878.

Liobikienè, G., Mandravickaite, J. and Bernatonienė, J. (2016), "Theory of planned behavior approach to understand the green purchasing behavior in the EU: A cross-cultural study", Ecological Economics, Vol. 125, pp. 38-46.

Lombart, C. and Louis, D. (2012), "Consumer satisfaction and loyalty: Two main consequences of retailer personality", Journal of Retailing and Consumer Services, Vol. 19 No. 6, pp. 644-652.

Lombart, C. and Louis, D. (2014), “A study of the impact of Corporate Social Responsibility and price image on retailer personality and consumers' reactions (satisfaction, trust and loyalty to the retailer)", Journal of Retailing and Consumer Services, Vol. 21 No. 4, pp. 630-642.

Louis, D., Lombart, C. and Durif, F. (2019), "Impact of a retailer's CSR activities on consumers' loyalty", International Journal of Retail \& Distribution Management, Vol. 47 No. 8, pp. 793-816.

Lu, Y.C. and Chen, K.N. (2017), "Consumer knowledge, brand image, openness to experience and involvement: A case in cosmetic consumption", Journal of Cosmetics, Dermatological Sciences and Applications, Vol. 7, p. 349-361.

MacKenzie, S.B. and Lutz, R.J. (1989), "An empirical examination of the structural antecedents of attitude toward the ad in an advertising pretesting context", Journal of Marketing, Vol. 53 No. 2, pp. 48-65. 
Maheswaran, D. and Meyers-Levy, J. (1990), "The influence of message framing and issue involvement", Journal of Marketing Research, Vol. 27 No. 3, pp. 361-367.

Marcoux, D. (2000), "Appearance, cosmetics, and body art in adolescents", Dermatologic Clinics, Vol. 18 No. 4, pp. 667-673.

Moussa, S. and Touzani, M. (2008), "The perceived credibility of quality labels: A scale validation with refinement", International Journal of Consumer Studies, Vol. 32 No. 5, pp. 526-533.

Newburger, A.E. (2009), "Cosmeceuticals: Myths and misconceptions", Clinics in Dermatology, Vol. 27 No. 5, pp. 446-452.

Nisbet, E.K., Zelenski, J.M. and Murphy, S.A. (2009), "The nature relatedness scale: Linking individuals' connection with nature to environmental concern and behavior", Environment and Behavior, Vol. 41 No. 5, pp. 715-740.

Ormandy, E. and Schuppli, C. (2014), "Public attitudes toward animal research: A review", Animals, Vol. 4 No. 3, pp. 391-408.

Ortega, D.L. and Wolf, C.A. (2018), "Demand for farm animal welfare and producer implications: Results from a field experiment in Michigan”, Food Policy, Vol. 74, pp. 74-81.

Padel, S. and Foster, C. (2005), "Exploring the gap between attitudes and behaviour", British Food Journal, Vol. 107 No. 8, pp. 606-625.

Petty, R.E. and Cacioppo, J.T. (1986), Communication and persuasion: Central and peripheral routes to attitude change, Springer, New York.

Photcharoen, C., Chung, R. and Sann, R. (2020), "Modelling Theory of Planned Behavior on health concern and health knowledge toward purchase intention on organic products", International Business Research, Vol. 13 No. 8, pp. 100-100.

Redondo Palomo, R., Valor Martínez, C. and Carrero Bosch, I. (2015), "The influence of social and environmental labels on purchasing: An information and systematic-heuristic processing approach", Innovar, Vol. 25 No. 57, pp. 121-132.

Roe, B., Levy, A.S. and Derby, B.M. (1999), "The impact of health claims on consumer search and product evaluation outcomes: Results from FDA experimental data", Journal of Public Policy \& Marketing, Vol. 18, No. 1, pp. 89-105.

Schröder, M.J. and McEachern, M.G. (2004), "Consumer value conflicts surrounding ethical food purchase decisions: A focus on animal welfare", International Journal of Consumer Studies, Vol. 28 No. 2, pp. 168-177.

Schuitema, G. and De Groot, J.I. (2015), "Green consumerism: The influence of product attributes and values on purchasing intentions", Journal of Consumer Behaviour, Vol. 14 No. 1, pp. 57-69.

Shamsher, R. and Chowdhury, R.A. (2012), "Relationship of demographic characteristics with purchasing decision involvement: A study on FMCG laundry soaps", Journal of Business \& Retail Management Research, Vol. 6 No. 2, pp. 78-89.

Sheehan, K.B. and Lee, J. (2014), "What's cruel about cruelty free: An exploration of consumers, moral heuristics, and public policy", Journal of Animal Ethics, Vol. 4 No. 2 , pp. 1-15.

Shim, S. and Eastlick, M.A. (1998), "The hierarchical influence of personal values on mall shopping attitute and behavior", Journal of Retailing, Vol. 74 No. 1, pp. 139-160.

Spooner, J.M., Schuppli, C.A. and Fraser, D. (2014), "Attitudes of Canadian citizens toward farm animal welfare: A qualitative study", Livestock Science, Vol. 163, pp. 150-158.

Sreedhar, D., Manjula, N., Ajay Pise, S.P. and Ligade, V.S. (2020), "Ban of cosmetic testing on animals: A brief overview", International Journal of Current Research and Review, Vol. 12 No. 14, p. 113. 
Te Velde, H., Aarts, N. and Van Woerkum, C. (2002), "Dealing with ambivalence: Farmers' and consumers' perceptions of animal welfare in livestock breeding", Journal of Agricultural and Environmental Ethics, Vol. 15 No. 2, pp. 203-219.

Tenenhaus, M., Esposito Vinzi, V., Chatelin, Y.M. and Lauro, C. (2005), "PLS path modeling”, Computational Statistics Data Analysis, Vol. 48 No. 1, pp. 159-205.

Thøgersen, J. and Ölander, F. (2003), "Spillover of environment-friendly consumer behaviour", Journal of Environmental Psychology, Vol. 23 No. 3, pp. 225-236.

Todd, A.M. (2004), "The aesthetic turn in green marketing: Environmental consumer ethics of natural personal care products", Ethics and the Environment, Vol. 9 No. 2, pp. 86102.

Van Giesen, R. and Leenheer, J. (2019), "Towards more interactive and sustainable food retailing. An empirical case study of the supermarket of the future", International Journal of Retail \& Distribution Management, Vol. 47 No. 1, pp. 55-75.

Van Riemsdijk, L., Ingenbleek, P., Van Trijp, H. and Van der Veen, G. (2017), "Marketing animal-friendly products: Addressing the consumer social dilemma with reinforcement positioning strategies", Animals, Vol. 7 No. 12, p. 98.

Wang, T., Mukhopadhyay, A. and Patrick, V.M. (2017), "Getting consumers to recycle NOW! When and why cuteness appeals influence prosocial and sustainable behavior", Journal of Public Policy \& Marketing, Vol. 36 No. 2, pp. 269-283.

Wansink, B., Sonka, S.T. and Hasler, C.M. (2004), "Front-label health claims: When less is more", Food Policy, Vol. 29 No. 6, pp. 659-667.

Zander, K. and Hamm, U. (2010), "Consumer preferences for additional ethical attributes of organic food", Food Quality and Preference, Vol. 21 No. 5, pp. 495-503.

Zeithaml, V.A., Berry, L.L. and Parasuraman, A. (1996), "The behavioral consequences of service quality", Journal of Marketing, Vol. 60 No. 2, pp. 31-46. 


\section{Figure 1: Research model}

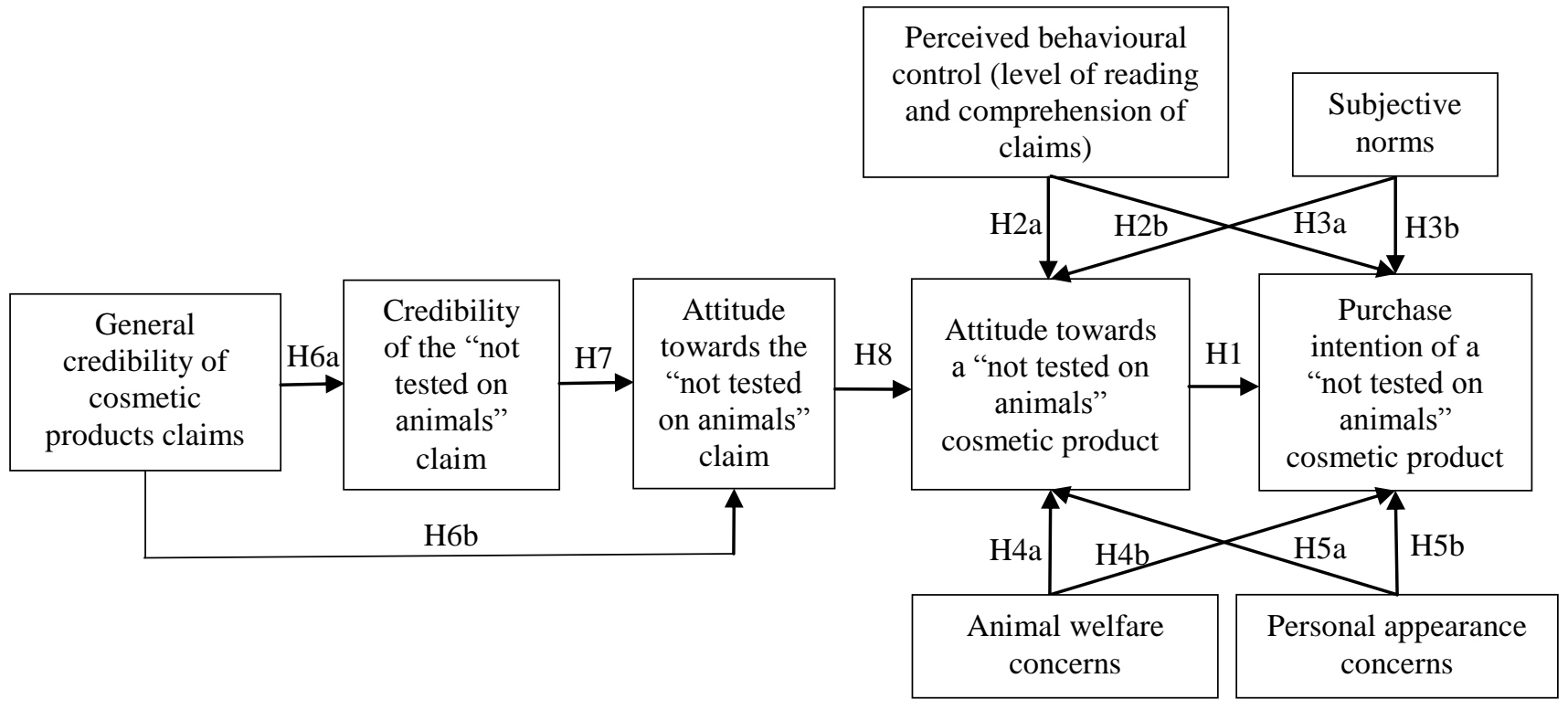


Figure 2: "Not tested on animals" claim model

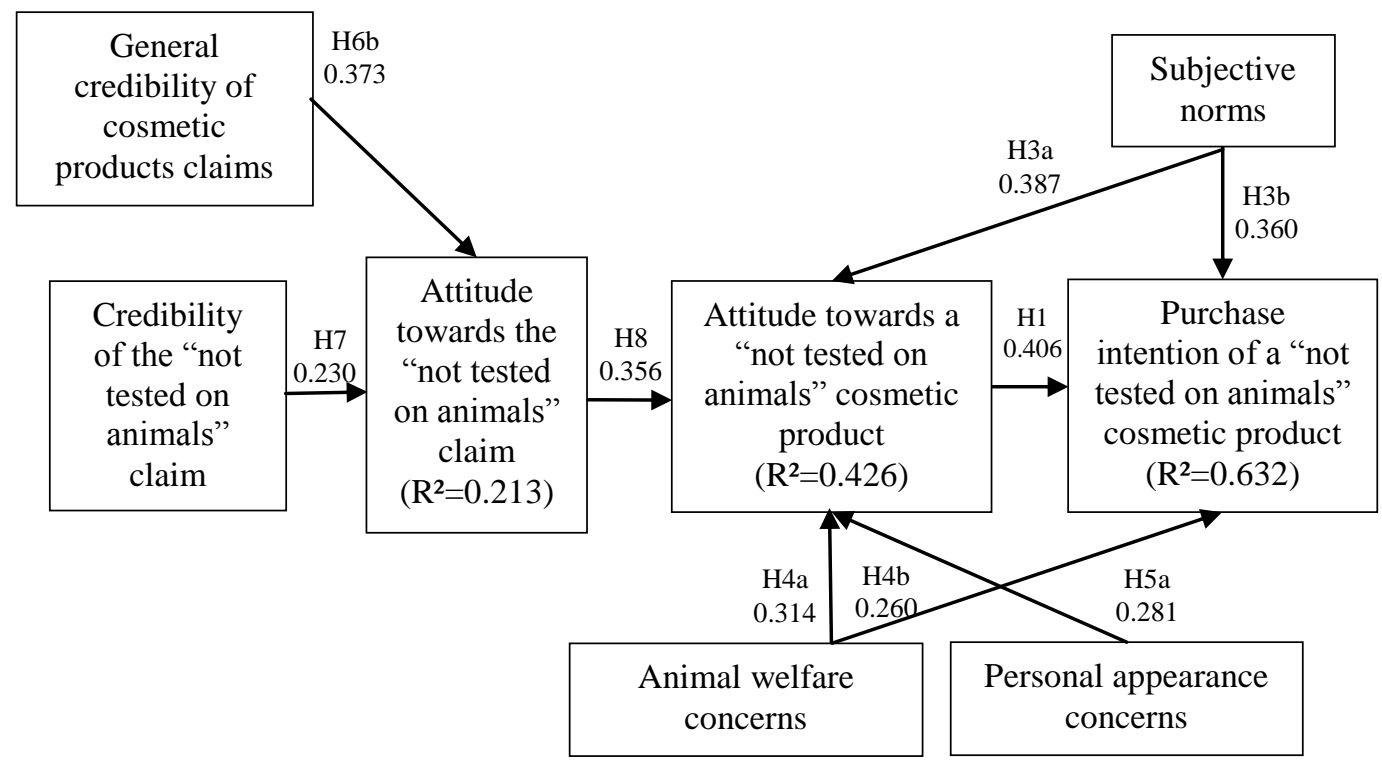


Figure 3: Control group model

\begin{tabular}{|c|c|c|}
$\begin{array}{c}\text { Attitude towards } \\
\text { the product } \\
\left(\mathrm{R}^{2}=0.424\right)\end{array}$ & $\begin{array}{c}\text { Purchase } \\
\text { intention } \\
\left(\mathrm{R}^{2}=0.691\right)\end{array}$ \\
& $\begin{array}{c}\text { Subjective } \\
\text { norms }\end{array}$ \\
\hline 0.596
\end{tabular}


Table 1: Socio-demographic characteristics of the control and manipulation groups

\begin{tabular}{|c|c|c|c|c|}
\hline & & $\begin{array}{c}\text { Total sample } \\
(\mathrm{n}=450)\end{array}$ & $\begin{array}{l}\text { Control group } \\
(\mathrm{n}=224)\end{array}$ & $\begin{array}{l}\text { Manipulation group } \\
(\mathrm{n}=226)\end{array}$ \\
\hline \multirow{2}{*}{ Sex } & Female & $82.6 \%$ & $85.7 \%$ & $79.8 \%$ \\
\hline & Male & $17.4 \%$ & $14.3 \%$ & $20.2 \%$ \\
\hline \multirow{3}{*}{ Age group } & Under 24 & $26.1 \%$ & $30.8 \%$ & $31.3 \%$ \\
\hline & $25-44$ & $67.2 \%$ & $62.6 \%$ & $61.9 \%$ \\
\hline & Over 45 & $6.7 \%$ & $6.6 \%$ & $6.7 \%$ \\
\hline \multirow{3}{*}{ Occupation } & Single & $50.7 \%$ & $51.6 \%$ & $49.4 \%$ \\
\hline & Common-law or married & $48.5 \%$ & $47.2 \%$ & $49.6 \%$ \\
\hline & Separated or divorced & $0.8 \%$ & $1.2 \%$ & $1 \%$ \\
\hline
\end{tabular}


Table 2: Results of confirmatory factor analyses

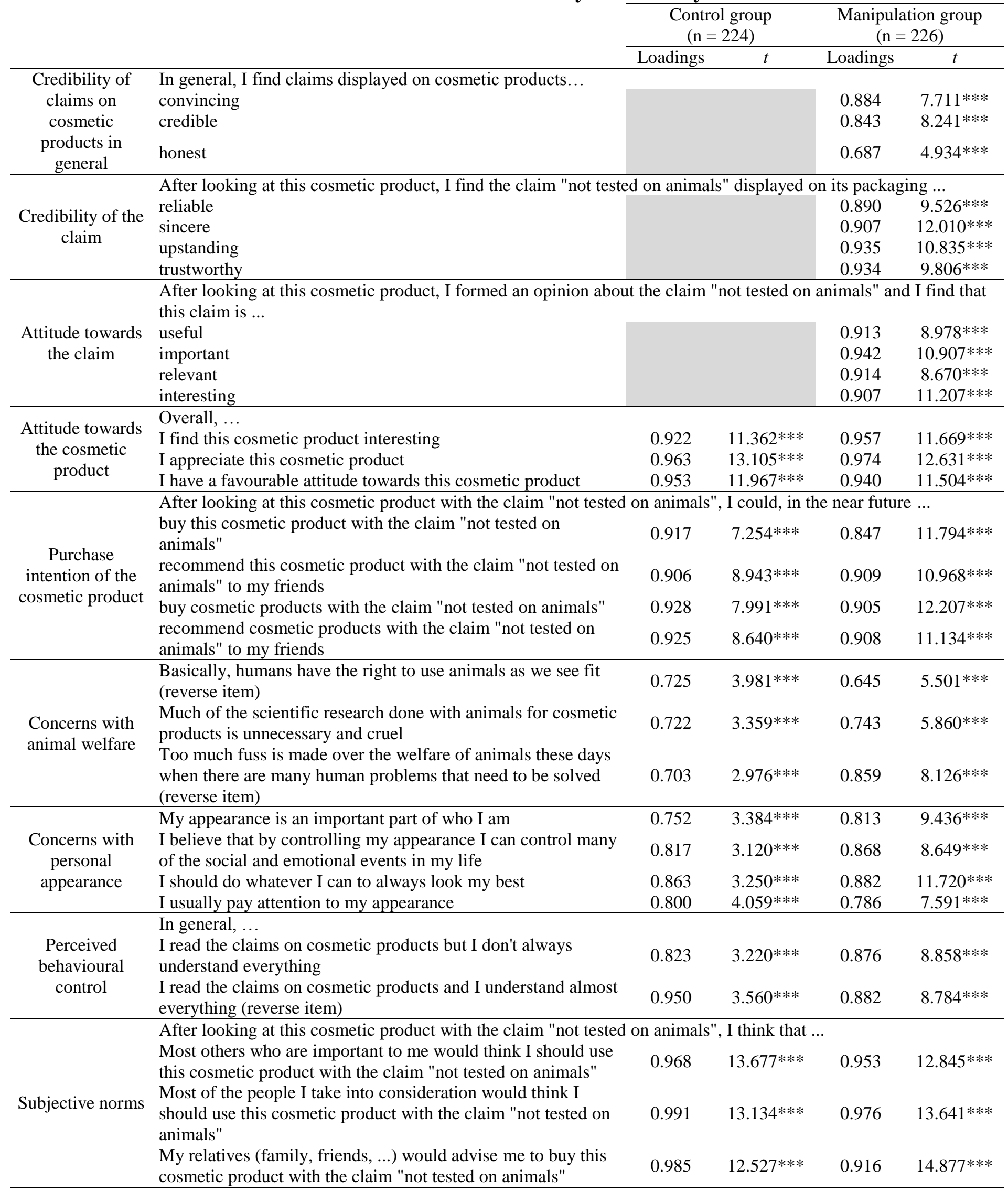

Note: Student's $t$ test values greater than $|2.575|$ indicate loadings significant at the $1 \%$ level (***). 
Table 3: Tests of reliability and convergent validity

\begin{tabular}{|c|c|c|c|c|c|c|}
\hline & \multicolumn{3}{|c|}{$\begin{array}{l}\text { Control group } \\
(\mathrm{n}=224)\end{array}$} & \multicolumn{3}{|c|}{$\begin{array}{l}\text { Manipulation group } \\
(\mathrm{n}=226)\end{array}$} \\
\hline & $\begin{array}{c}\text { Cronbach } \\
\text { alpha }\end{array}$ & $\begin{array}{c}\text { Jöreskog } \\
\text { rhô }\end{array}$ & AVE & $\begin{array}{c}\text { Cronbach } \\
\text { alpha }\end{array}$ & $\begin{array}{c}\text { Jöreskog } \\
\text { rhô }\end{array}$ & AVE \\
\hline Credibility of claims on cosmetic products in general & & & & 0.743 & 0.859 & 0.655 \\
\hline Credibility of the claim & & & & 0.934 & 0.954 & 0.840 \\
\hline Attitude towards the claim & & & & 0.938 & 0.956 & 0.845 \\
\hline Attitude towards the cosmetic product & 0.941 & 0.962 & 0.895 & 0.954 & 0.971 & 0.916 \\
\hline Purchase intention of the cosmetic product & 0.939 & 0.956 & 0.845 & 0.915 & 0.941 & 0.796 \\
\hline Concerns with animal welfare & 0.777 & 0.747 & 0.513 & 0.730 & 0.814 & 0.569 \\
\hline Concerns with personal appearance & 0.835 & 0.893 & 0.655 & 0.837 & 0.907 & 0.703 \\
\hline Perceived behavioural control & 0.753 & 0.890 & 0.790 & 0.706 & 0.872 & 0.773 \\
\hline Subjective norms & 0.981 & 0.988 & 0.963 & 0.944 & 0.964 & 0.900 \\
\hline
\end{tabular}

Note: AVE = Average Variance extracted. 
Table 4: Test of discriminant validity

\begin{tabular}{|c|c|c|c|c|c|c|c|c|c|c|}
\hline \multicolumn{2}{|l|}{$\begin{array}{c}\text { Control group } \\
(\mathrm{n}=224)\end{array}$} & 1. & 2. & 3. & 4. & 5. & 6. & 7. & 8. & 9. \\
\hline \multicolumn{11}{|c|}{ 1. Credibility of claims on cosmetic products in general } \\
\hline \multicolumn{11}{|c|}{ 2. Credibility of the claim } \\
\hline \multicolumn{11}{|l|}{ 3. Attitude towards the claim } \\
\hline \multicolumn{11}{|l|}{ 4. Attitude towards the cosmetic product } \\
\hline \multicolumn{11}{|l|}{ 5. Purchase intention of the cosmetic product } \\
\hline \multicolumn{11}{|l|}{ 6. Concerns with animal welfare } \\
\hline \multicolumn{11}{|l|}{ 7. Concerns with personal appearance } \\
\hline \multicolumn{11}{|l|}{ 8. Perceived behavioural control } \\
\hline \multicolumn{5}{|l|}{ 9. Subjective norms } & 0.789 & 0.836 & -0.220 & 0.207 & -0.120 & 1 \\
\hline $\begin{array}{c}\text { Manipulation group } \\
(\mathrm{n}=226)\end{array}$ & 1. & 2. & 3. & 4. & 5. & 6. & 7. & 8. & 9. & \\
\hline ity of claims on cosmetic products in general & 1 & & & & & & & & & \\
\hline ity of the claim & 0.123 & 1 & & & & & & & & \\
\hline towards the claim & 0.409 & 0.294 & 1 & & & & & & & \\
\hline towards the cosmetic product & 0.162 & 0.534 & 0.572 & 1 & & & & & & \\
\hline e intention of the cosmetic product & 0.361 & 0.241 & 0.671 & 0.702 & 1 & & & & & \\
\hline s with animal welfare & 0.197 & 0.091 & 0.474 & 0.158 & 0.509 & 1 & & & & \\
\hline s with personal appearance & 0.232 & 0.173 & 0.087 & 0.145 & -0.113 & 0.202 & 1 & & & \\
\hline d behavioural control & -0.235 & -0.096 & -0.075 & -0.033 & -0.019 & -0.078 & -0.023 & 1 & & \\
\hline ve norms & 0.143 & 0.197 & 0.537 & 0.590 & 0.725 & 0.431 & 0.184 & 0.038 & 1 & \\
\hline
\end{tabular}


Table 5: Results of structural equation model

\begin{tabular}{|c|c|c|c|c|c|c|}
\hline \multirow{2}{*}{\multicolumn{4}{|c|}{$\begin{array}{c}\text { Control group } \\
(\mathrm{n}=224)\end{array}$}} & \multicolumn{3}{|c|}{$\begin{array}{l}\text { Manipulation group } \\
(\mathrm{n}=226)\end{array}$} \\
\hline & & & & PC & $t$ & $\mathrm{R}^{2}$ \\
\hline Credibility of claims on cosmetic products in general $\rightarrow$ Credibility of the claim & & & & 0.179 & ns & 0.024 \\
\hline Credibility of the claim $\rightarrow$ Attitude towards the claim & & & & 0.230 & $2.365 * *$ & \\
\hline Credibility of claims on cosmetic products in general $\rightarrow$ Attitude towards the claim & & & & 0.373 & $3.792 * * *$ & 0.213 \\
\hline Attitude towards the claim $\rightarrow$ Attitude towards the cosmetic product & & & & 0.356 & $3.747 * * *$ & \\
\hline Concerns about animal welfare $\rightarrow$ Attitude towards the cosmetic product & 0.145 & ns & & 0.314 & $3.343 * * *$ & \\
\hline Concerns about personal appearance $\rightarrow$ Attitude towards the cosmetic product & -0.077 & ns & & 0.281 & $3.330 * * *$ & 0.426 \\
\hline Perceived behavioural control $\rightarrow$ Attitude towards the cosmetic product & -0.041 & ns & 0.424 & 0.001 & ns & \\
\hline Subjective norms $\rightarrow$ Attitude towards the cosmetic product & 0.748 & $10.969 * * *$ & & 0.387 & $3.852 * * *$ & \\
\hline Concerns about animal welfare $\rightarrow$ Purchase intention of the cosmetic product & -0.028 & ns & & 0.260 & $3.663 * * *$ & \\
\hline Concerns about personal appearance $\rightarrow$ Purchase intention of the cosmetic product & 0.011 & ns & & -0.028 & ns & \\
\hline Perceived behavioural control $\rightarrow$ Purchase intention of the cosmetic product & -0.103 & ns & & -0.029 & ns & \\
\hline Subjective norms $\rightarrow$ Purchase intention of the cosmetic product & 0.596 & $6.184 * * *$ & 0.691 & 0.360 & $4.253 * * *$ & 0.632 \\
\hline Attitude towards the cosmetic product $\rightarrow$ Purchase intention of the cosmetic product & 0.289 & $2.862 * * *$ & & 0.406 & $5.202 * * *$ & \\
\hline
\end{tabular}

